\title{
Ceria-Based Solid Electrolytes for IT-SOFC Applications
}

\author{
A. ArABACI* \\ Istanbul University-Cerrahpasa, Engineering Faculty, Department of Metallurgical and Materials Eng., \\ 34320 Avcilar-Istanbul/Turkey
}

\begin{abstract}
In this study, doped ceria solid electrolyte materials $\mathrm{Ce}_{0.8} \mathrm{M}_{0.2} \mathrm{O}_{2-\delta}(\mathrm{M}=\mathrm{Gd}, \mathrm{Sm}$, and $\mathrm{Nd})$ for intermediate temperature-solid oxide fuel cells were synthesized through citrate-nitrate auto combustion method. They were then characterized by X-ray diffraction (XRD), scanning electron microscope (SEM), and Fourier transform infrared (FT-IR) techniques. XRD results show that all the synthesized powders indicate a single-phase with cubic fluorite structure. Electrolytes with high density were obtained by sintering the samples at $1400{ }^{\circ} \mathrm{C}$ for $6 \mathrm{~h}$. The mean crystallite sizes were calculated using the Scherrer formula. Surface morphologies of all the sintered electrolytes were obtained by using SEM. The total ionic conductivity of all electrolytes was measured from the impedance analysis in $300-700{ }^{\circ} \mathrm{C}$ temperature range. The ionic conductivities at $700{ }^{\circ} \mathrm{C}$ are in the order of $\mathrm{Ce}_{0.8} \mathrm{Sm}_{0.2} \mathrm{O}_{2-\delta}>\mathrm{Ce}_{0.8} \mathrm{Gd}_{0.2} \mathrm{O}_{2-\delta}>\mathrm{Ce}_{0.8} \mathrm{Nd}_{0.2} \mathrm{O}_{2-\delta}$, and their corresponding activation energies are found to be $0.61,0.62$, and $0.67 \mathrm{eV}$, respectively.
\end{abstract}

DOI: 10.12693/APhysPolA.137.530

PACS/topics: Rare earth, XRD, SEM, Dopant, Electrolyte

\section{Introduction}

Ceria is a main component of a solid oxide electrolyte. A solid electrolyte as an oxide ion conductor is the main component of a solid-oxide fuel cell (SOFC) which can be considered as a promising device due to its high efficiency and environmental friendly nature $[1-5]$. The electrolyte material is sandwiched between the cathodes and anodes. At high temperatures, zirconium oxide-based materials are commonly used as solid oxide electrolytes in SOFC applications. This is because of their excellent ionic conductivity, high chemical and mechanical stability. However, high operating temperatures induce high costs, differences in thermal expansion coefficients and lead to reactions between the cell components [6]. As mentioned before, solid oxide ion electrolyte material plays a crucial role based on IT-SOFC. Therefore, it is required to reduce the operating temperature and develop novel solid oxide ion conductors for the intermediate temperature range $\left(500-700^{\circ} \mathrm{C}\right)$ to advance the SOFC technology.

Fluorite structured ceria doped with rare earth has been revealed to be a promising electrolyte material for IT-SOFCs operating at $<700{ }^{\circ} \mathrm{C}[7,8]$. Ceria doped with gadolinia and ceria doped with samarium have been reported to possess the highest ionic conductivity [9], among the other rare earth elements doped ceria. On the other hand, Kamiya et al. reported that the oxygen diffusion co-efficient of ceria doped with $\mathrm{Nd}$ is larger than that of ceria doped with Gd, and many other rare earth elements with the same amount.

If cubic flourite ceria is doped with alkaline earth and rare earth oxides, oxygen vacancy is introduced in

\footnotetext{
*e-mail: aliye@istanbul.edu.tr
}

the host lattice to maintain the charge balance. The defect reaction can be described in Kröger-Vink notation as given below for addition of $\mathrm{M}(\mathrm{M}=\mathrm{Gd}, \mathrm{Sm}, \mathrm{Nd})$ in the ceria matrix,

$$
\mathrm{M}_{2} \mathrm{O}_{3} \stackrel{2 \mathrm{CeO}_{2}}{\longrightarrow} 2 \mathrm{M}_{\mathrm{Ce}}^{\prime}+3 \mathrm{O}_{\mathrm{o}}^{\mathrm{x}}+\mathrm{V}_{\mathrm{o}}^{\bullet \bullet}
$$

where $\mathrm{M}_{\mathrm{Ce}}^{\prime}$ shows one $\mathrm{Ce}^{4+}$ site that is replaced with $\mathrm{M}^{3+}$ ion. In fact, undoped ceria is a poor ionic conductor. When ceria is doped with rare earth cations, it may cause an increase in the oxygen vacancies which results in the increase of the ionic conductivity of $\mathrm{CeO}_{2}$ to keep the charge balance.

In doped ceria with the fluorite type structure, the ionic conduction is realized via an oxygen vacancy diffusion mechanism. Oxygen ions' diffusion within the fluorite structure can be described as an thermally activated process with characteristic activation energy.

The ionic conductivity properties of the doped ceria can be significantly influenced by the type and amount of the dopant elements, sintering temperature, and the synthesis method. Also, the ionic conductivity of doped ceria is appreciably affected by the microstructure features such as the grain size [10].

Synthesizing ultrafine doped ceria powder is crucial to achieve dense electrolyte materials by sintering. According to the literature, doped cerium dioxide powders can be produced with a variety of techniques such as sol gel method, hydrothermal, coprecipitation, and combustion [11-13]. These reported processes are capable of synthesizing ultra-fine powders with narrow size distributions. Combustion synthesis is a wet chemical process that provides the possibility of obtaining ultra-fine doped cerium oxide powders with superior compositional homogeneity and easy controllability [14, 15].

The main advantages of this process are fewer stages and better control of stoichiometry while producing powders in the nanometer range. Citric acid, which 
is more cost-effective than the other organic fuels, acts as a complexing agent for a number of metal ions as it possess three carboxyl groups and one hydroxyl group. On the other hand, citric acid can also serve as fuel in the combustion reaction.

In this paper, $\mathrm{Gd}^{3+}, \mathrm{Sm}^{3+}$, and $\mathrm{Nd}^{3+}$ rare earth ions are used as dopants. Dopant amount was fixed at $20 \%$. Doped ceria-based $\mathrm{Ce}_{0.8} \mathrm{M}_{0.2}(\mathrm{M}=\mathrm{Gd}, \mathrm{Sm}, \mathrm{Nd}) \mathrm{O}_{2-\delta}$, materials were prepared by the citrate-complexation method, and characterized. Effects of the rare earth elements on $\mathrm{CeO}_{2}$ are investigated by studying their structure with XRD, microstructure with SEM, and ionic conductivity with impedance spectroscopy. In order to enhance the performance of the solid oxide fuel cells for intermediate-temperature applications, such as rare earth ions $\mathrm{Gd}^{3+}, \mathrm{Sm}^{3+}$, and $\mathrm{Nd}^{3+}$, are more suitable as dopant ions.

\section{Materials and method}

$\mathrm{Ce}_{0.8} \mathrm{Sm}_{0.2} \mathrm{O}_{1.90}$ (SDC), $\mathrm{Ce}_{0.8} \mathrm{Gd}_{0.2} \mathrm{O}_{1.90}$ (GDC), and $\mathrm{Ce}_{0.8} \mathrm{Nd}_{0.2} \mathrm{O}_{1.90}$ (NDC) samples were synthesized by using the low temperature citrate-complexation method as described in our previous work [16]. Cerium nitrate salt $\left(\mathrm{Ce}\left(\mathrm{NO}_{3}\right)_{3} \cdot 6 \mathrm{H}_{2} \mathrm{O}\right.$, Aldrich, 99.99\%), gadolinium nitrate salt $\left(\mathrm{Gd}\left(\mathrm{NO}_{3}\right)_{3} \cdot 6 \mathrm{H}_{2} \mathrm{O}\right.$, Aldrich, 99.99\%), neodymium $\left(\mathrm{Nd}\left(\mathrm{NO}_{3}\right)_{3} \cdot 6 \mathrm{H}_{2} \mathrm{O}\right.$, Aldrich, 99.9\%), and anhydrous $\mathrm{C}_{6} \mathrm{H}_{8} \mathrm{O}_{7}$ were used as starting materials. The molar ratio of the cations to citric acid was 1:1.

To produce the SDC, GDC, NDC electrolyte samples, calculated amounts of metal salts were dissolved in deionized water to acquire a transparent solution. Then, anhydrous citric acid was added into the solution at 1:1 molar ratio with the cations, as a chelating agent and fuel, as well. These solutions were constantly stirred for approximately $30 \mathrm{~min}$ with a magnetic stirrer The solution was heated up to $85^{\circ} \mathrm{C}$ utilizing a hot plate until the yellowish gel was obtained. After that, the gel was dried in an oven. The dried gel was heated in a furnace at $300{ }^{\circ} \mathrm{C}$ for $2 \mathrm{~h}$ under air atmosphere and self-ignited until the yellow powders were produced. The generated yellow powders were calcined at $600{ }^{\circ} \mathrm{C}$ to achieve powders without carbonaceous elements.

The synthesized powders were calcined at $600{ }^{\circ} \mathrm{C}$ for $3 \mathrm{~h}$ to remove the carbon residues and form a well crystalline fuorite structure. Then the powders were pressed with a hydraulic press under $50 \mathrm{~N} / \mathrm{mm}^{2}$ to prepare green pellets with $10 \mathrm{~mm}$ diameter and $1.5 \mathrm{~mm}$ thickness. Then, the pellets were sintered at $1400^{\circ} \mathrm{C}$ for $6 \mathrm{~h}$. After that, these disc-shaped pellets were pressed by cold isostatic press under $200 \mathrm{~N} / \mathrm{mm}^{2}$. Finally, the obtained pellets were sintered at $1400^{\circ} \mathrm{C}$ for $6 \mathrm{~h}$ with $5^{\circ} \mathrm{C} / \mathrm{min}$ heating rate. Density values of the sintered solid oxide pellets were measured considering the Archimedes' principle and were estimated to be $>90 \%$ of theoretical density.

$\mathrm{X}$-ray diffraction measurements were conducted with a D/max-2200 ultima X-ray diffractometer (Rigaku) to check the phase purity and to determine the particle size and lattice parameter of the solid oxide electrolyte samples. Diffraction data of the doped ceria particles were recorded in a $2 \theta$ range from $10^{\circ}$ to $90^{\circ}$.

FT-IR analyses (with a Perkin Elmer Spectrrum 100 instrument) were carried out to study the structures of SDC, GDC, and NDC by using Potassium bromide pellet technique in the wave number range of $350-4000 \mathrm{~cm}^{-1}$.

Microstructures of the combustion powders and surfaces of the sintered pellets were observed using the scanning electron microscopy (FEI QUANTA FEG 450 scanning electron microscope).

$\mathrm{Ag}$ paste was applied to the both faces of the sintered pellets to prepare the electrode for the conductivity analyses, and the whole structure annealed at $800^{\circ} \mathrm{C}$ for $30 \mathrm{~min}$. The conductivity measurements of the sintered $\mathrm{M}(\mathrm{M}=\mathrm{Gd}, \mathrm{Sm}, \mathrm{Nd})$ doped cerium oxide pellets were performed in a tube furnace by using two probe methods in the air. AC impedance analyser SOLARTRON 1260 FRA was used to carry out the measurements in a frequency range of $10 \mathrm{MHz}$ to $100 \mathrm{mHz}$. The ionic conductivity measurements of the sintered pellets were taken within $50^{\circ} \mathrm{C}$ intervals in the temperature range of $300^{\circ} \mathrm{C}$ to $800^{\circ} \mathrm{C}$ in the air. Data were collected with SMART program and fitted to the corresponding equivalent circuits with the ZView Program. A complex plane plot of real impedance $\left(Z^{\prime}\right)$ versus imaginary impedance $\left(Z^{\prime \prime}\right)$ was prepared for each set of data.

Overall resistance of the electrolyte is given by

$$
R_{\text {overall }}=R_{\mathrm{g}}+R_{\mathrm{gb}}
$$

where $R_{\text {overall }}$ is the total resistance, $R_{\mathrm{g}}$ is the grain resistance, and $R_{\mathrm{gb}}$ represents the grain boundary resistance.

Then, the conductivity can be calculated with

$$
\sigma=\frac{l}{S} R_{\text {overall }}
$$

where $l$ and $\mathrm{S}$ are the sample thickness and the area of the sample surface, respectively.

\section{Results and discussions}

\subsection{Crystal structure}

Figure 1 depicts the X-ray diffraction patterns of $\mathrm{Ce}_{0.8} \mathrm{Sm}_{0.2} \mathrm{O}_{1.90}, \mathrm{Ce}_{0.8} \mathrm{Gd}_{0.2} \mathrm{O}_{1.90}, \mathrm{Ce}_{0.8} \mathrm{Nd}_{0.2} \mathrm{O}_{1.90}$ solid oxide electrolyte samples calcined at $600^{\circ} \mathrm{C}$ for $3 \mathrm{~h}$. All diffraction peaks are well indexed (JCPDS no. 34-0394) to the single phase with cubic fluorite structure. No additional phases corresponding to $\mathrm{Gd}_{2} \mathrm{O}_{3}, \mathrm{Sm}_{2} \mathrm{O}_{3}$, or $\mathrm{Nd}_{2} \mathrm{O}_{3}$ were observed which ensured the complete dissolution of the dopant elements in the cerium oxide lattice. The mean crystallite sizes calculated by using the Scherrer formula were 12,17 , and $19.2 \mathrm{~nm}$ for $\mathrm{Ce}_{0.8} \mathrm{Sm}_{0.2} \mathrm{O}_{1.90}$, $\mathrm{Ce}_{0.8} \mathrm{Gd}_{0.2} \mathrm{O}_{1.90}$, and $\mathrm{Ce}_{0.8} \mathrm{Nd}_{0.2} \mathrm{O}_{1.90}$, respectively.

The introduction of $\mathrm{Sm}^{3+}, \mathrm{Gd}^{3+}$, and $\mathrm{Nd}^{3+}$ ions into $\mathrm{Ce}^{4+}$ can cause a small shift in the cerium oxide peaks positions. X-ray peaks shifted toward the higher $2 \theta$ value. This shift was attributed to the increase of the ionic diameter of $\mathrm{Nd}^{3+}(1.109 \AA)>\mathrm{Sm}^{3+}(1.079 \AA)>$ $\mathrm{Gd}^{3+}(1.053 \AA)>\mathrm{Ce}^{4+}(0.970 \AA)$. Figure 1 shows the shift 


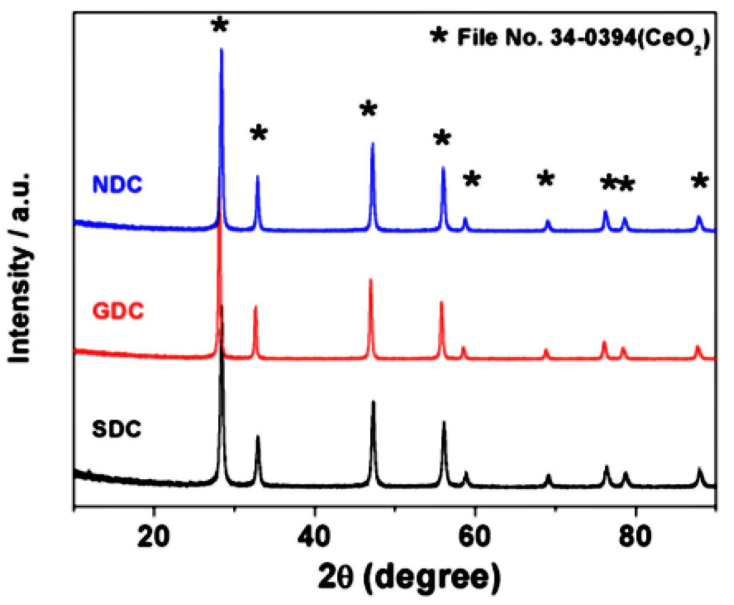

Fig. 1. XRD patterns of the calcined $\mathrm{Ce}_{0.8} \mathrm{Sm}_{0.2} \mathrm{O}_{1.90}$ (SDC), $\quad \mathrm{Ce}_{0.8} \mathrm{Gd}_{0.2} \mathrm{O}_{1.90}$ (GDC), $\mathrm{Ce}_{0.8} \mathrm{Nd}_{0.2} \mathrm{O}_{1.90}(\mathrm{NDC})$ powders.

of the peaks. This shift can be attributed to the change in the lattice parameter. Lattice parameters of the SDC, GDC, and NDC samples were calculated to be $5.425 \AA$, $5.437 \AA$, and $5.447 \AA$, respectively.

\subsection{Microstructure}

The microstructure of the sintered pellets of $\mathrm{Ce}_{0.8} \mathrm{M}_{0.2} \mathrm{O}_{1.90}(\mathrm{M}=\mathrm{Sm}, \mathrm{Gd}, \mathrm{Nd})$ was studied by SEM. SEM micrographs of the outher surfaces of the sintered $\mathrm{Ce}_{0.8} \mathrm{Sm}_{0.2} \mathrm{O}_{1.90}, \mathrm{Ce}_{0.8} \mathrm{Gd}_{0.2} \mathrm{O}_{1.90}, \mathrm{Ce}_{0.8} \mathrm{Nd}_{0.2} \mathrm{O}_{1.90}$ electrolyte samples are given in Fig. 2. It can be observed that NDC, GDC, and SDC samples are all well sintered. There are no pores recognized on the sample surfaces, which are consistent with the measured density of the sintered pellets. The sintered pellets have a relative density of $95 \%$. The average grain size of each sample was found to be in the range of $0.67-0.78 \mu \mathrm{m}$.

\subsection{Fourier transform infrared (FTIR) spectroscopy}

Fourier transform infrared (FTIR) spectra of the calcined SDC, GDC, and NDC powders are shown in Fig. 3. There are some distinctive absorptions peaks at 3430 and $1628 \mathrm{~cm}^{-1}$. In addition, some weaker absorption peaks were also observed at around 2930, 1092, and $700 \mathrm{~cm}^{-1}$.

The strong band at $3430 \mathrm{~cm}^{-1}$ is attributed to the $\nu(\mathrm{O}-\mathrm{H})$ vibration modes of the physically adsorbed water molecules. The less intense peaks at $2930 \mathrm{~cm}^{-1}$ are attributed to the stretching vibration of the $\mathrm{CH}_{2}$ group. Absorption at $1628 \mathrm{~cm}^{-1}$ is assigned to a systematic stretching vibration of the $\mathrm{COO}^{-}$group [17]. The peak at around $1090 \mathrm{~cm}^{-1}$ indicates the presence of the nitrate ions [18]. The bands observed in the lower frequency region at 700 and $430 \mathrm{~cm}^{-1}$ are referred to the characteristic $\mathrm{Ce}-\mathrm{O}$ vibration [19]. Although the presence of the $\mathrm{COO}^{-}$group and nitrate ions, a dense structure was obtained after sintering, as seen in Fig. 2.

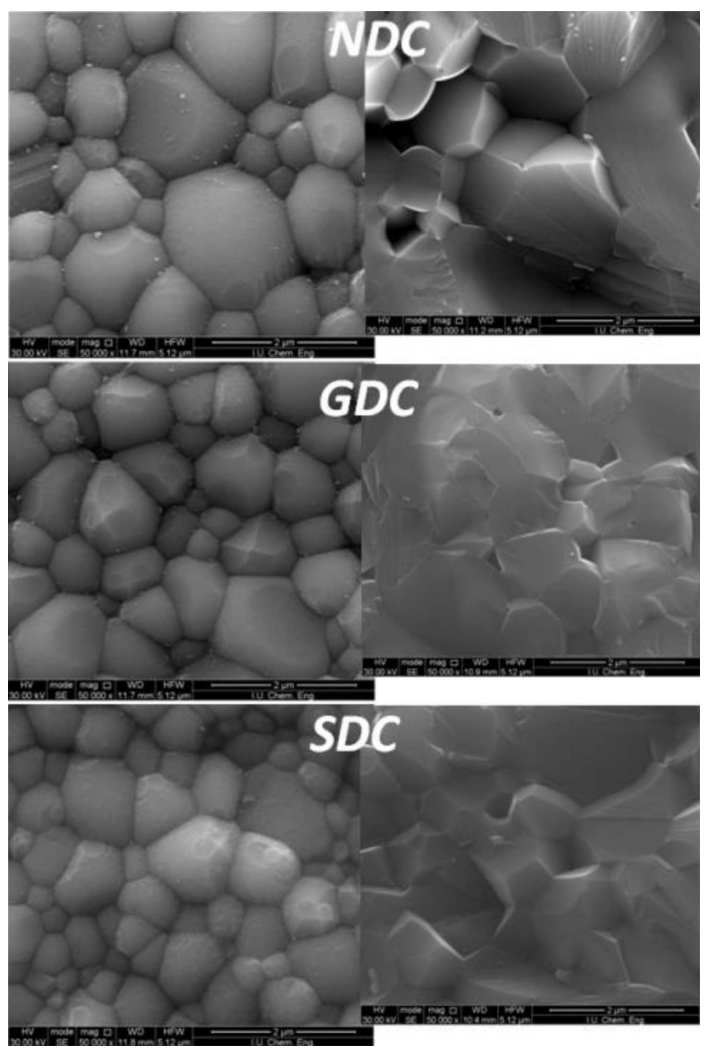

Fig. 2. SEM micrographs of SDC, GDC and NDC samples sintered at $1400^{\circ} \mathrm{C}$ in the air.

\subsection{Impedance results}

Electrical Impedance Spectroscopy (EIS) is a useful device to understand the electrical features of polycrystalline solid oxide electrolytes. EIS makes it possible to obtain information about the fuel cell system, i.e. anode, cathode, and the electrolyte. In Fig. 4a, contributions of three separate semi-circles are recognized. These semicircles belong to the grain, grain boundary, and electrode resistances, respectively, from left to right. At such a low operating temperature, i.e., $300^{\circ} \mathrm{C}$, three arcs can be observed in the Nyquist plot. However, as the operating temperature increases, the semicircle that corresponds to the grain resistivity disappears and only the grain and electrode resistivity are observed at $400-500^{\circ} \mathrm{C}$. Bulk resistivity could be calculated by measuring the distance between the origin and the starting point of the grain boundary semicircle. Beyond $500^{\circ} \mathrm{C}$, only the semicircle that represents the electrode remains and it is impossible to determine the bulk or grain resistivity separately. Therefore, only the total resistivity could be calculated at temperatures higher than $500^{\circ} \mathrm{C}$. The real axis intercept of high frequency arc delineates the grain resistance and intercept of intermediate frequency arc defines the grain boundary resistance. The total resistance is the sum of these two resistances. The total resistance of the electrolyte is given by (2), and the overall conductivity can be found using (3). 


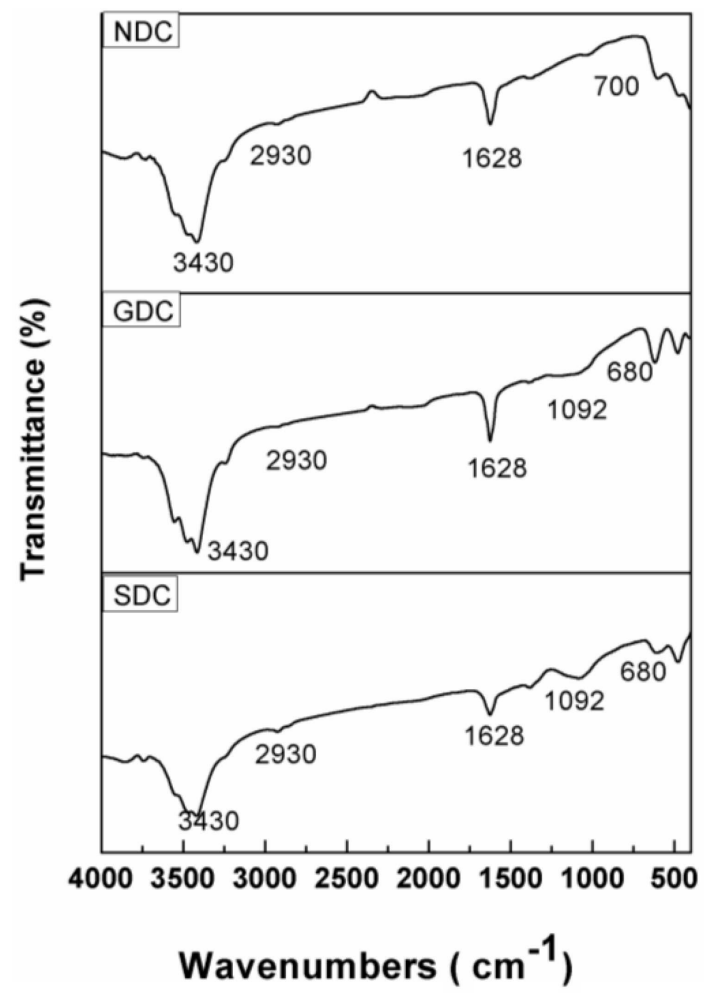

Fig. 3. FTIR spectra of the calcined $\mathrm{Ce}_{0.8} \mathrm{M}_{0.2} \mathrm{O}_{1.90}$ powders $(\mathrm{M}=\mathrm{Sm}, \mathrm{Gd}, \mathrm{Nd})$.

Figures $4 \mathrm{~b}$ and $4 \mathrm{c}$ show that the both grain and grain boundary resistance decrease with the increasing operating temperature. The decrease in the grain boundary resistance with the increasing temperature may arise from the lowering of the barrier that favors the increase of mobility of the charge carriers [20].

Activation energies $E$, which are the sum of the association energy $E_{a}$ and the migration energy $E_{m}$, were calculated by fitting the conductivity data to the Arrhenius relation for thermally activated conduction. This relation is given by

$$
\sigma=\frac{\sigma_{0}}{T} \exp \left(-\frac{E}{k_{\mathrm{B}} T}\right)
$$

where $\sigma_{0}$ is a pre-exponential factor being a constant in a certain temperature range, $T$ is the absolute temperature, $k_{\mathrm{B}}$ represents the Boltzman's constant, and $E$ is the activation energy of electrical conduction. This energy $E$ can be calculated from the slope of the Arrhenius plot. Figure 5 shows for all $\mathrm{Ce}_{0.8} \mathrm{M}_{0.2} \mathrm{O}_{2-\delta}(\mathrm{M}=\mathrm{Sm}, \mathrm{Gd}, \mathrm{Nd})$ samples that the conductivity values increase with temperature.

In Fig. 5, the Arrhenius plot of $\mathrm{Ce}_{0.8} \mathrm{M}_{0.2} \mathrm{O}_{1.90}$, doping with the Sm and Gd cations mentioned above, improved the total conductivity compared to cerium oxide doped with $\mathrm{Nd}$ cation. Among the current doping cations in this study, $\mathrm{Sm}^{3+}$ gave the best results $\left(\sigma_{\text {Total }}=2.77 \times 10^{-2} \mathrm{~S} / \mathrm{cm}\right.$ at intermediate temperature of $650{ }^{\circ} \mathrm{C}$ with $\left.E=0.61 \mathrm{eV}\right)$. This conductivity
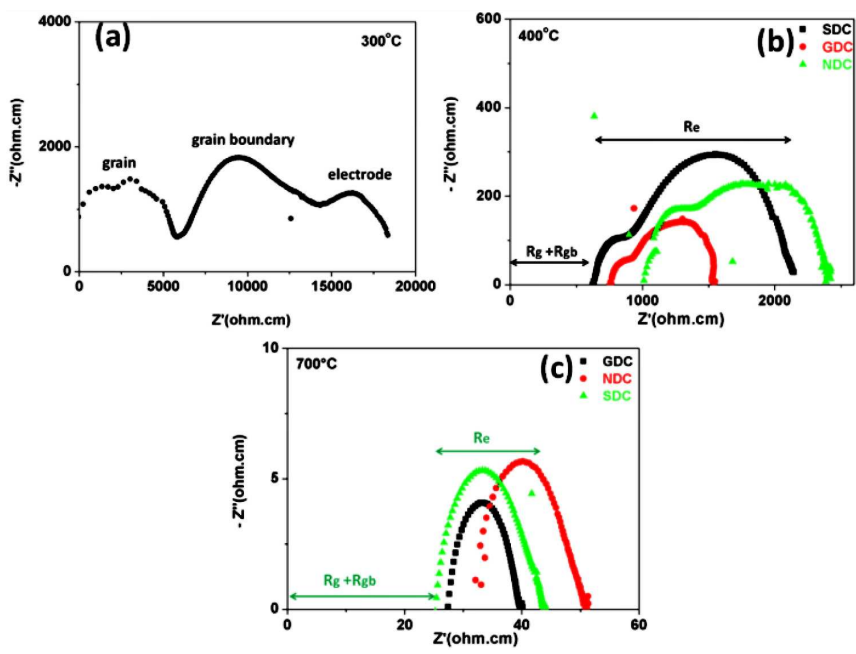

Fig. 4. (a) The impedance spectrum of SDC at $300^{\circ} \mathrm{C}$, the impedance spectrum of SDC, GDC and NDC samples (b) at 400 , and (c) $700{ }^{\circ} \mathrm{C}$.

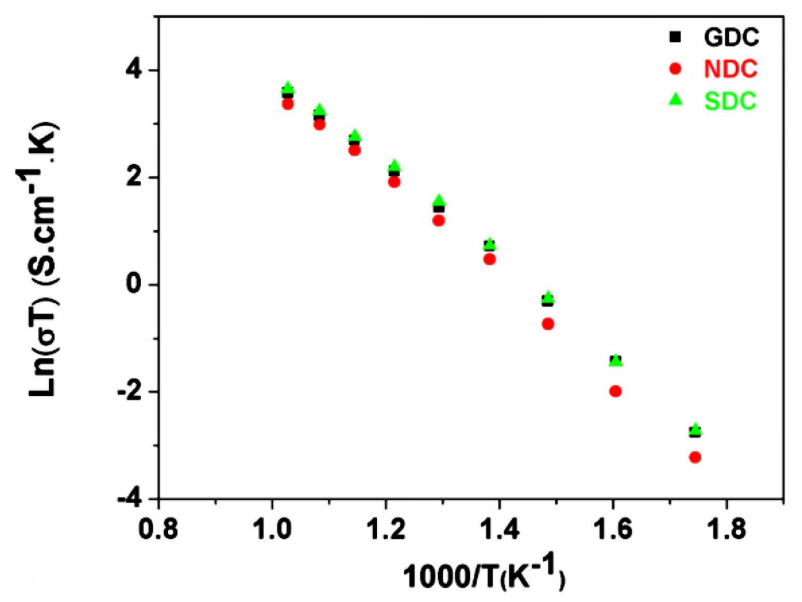

Fig. 5. Total electrical conductivity obtained for $\mathrm{Ce}_{0.8} \mathrm{M}_{0.2} \mathrm{O}_{1.90}(\mathrm{M}=\mathrm{Sm}, \mathrm{Gd}, \mathrm{Nd})$ electrolyte sintered at $1400^{\circ} \mathrm{C}$.

value is higher than the reported conductivity values of $\mathrm{Ce}_{0.85} \mathrm{Sm}_{0.15} \mathrm{O}_{2-\delta}$ (MS-SDC) $\left(1.44 \times 10^{-2} \mathrm{~S} / \mathrm{cm}\right)$, $\mathrm{Ce}_{0.85} \mathrm{La}_{0.15} \mathrm{O}_{2-\delta}(\mathrm{MS}-\mathrm{LDC})\left(1.30 \times 10^{-2} \mathrm{~S} / \mathrm{cm}\right)[20]$, and $\mathrm{Ce}_{0.80} \mathrm{Gd}_{0.20} \mathrm{O}_{1.90}\left(1.29 \times 10^{-2} \mathrm{~S} / \mathrm{cm}\right)[19]$ at $650^{\circ} \mathrm{C}$. Conductivity of $\mathrm{Ce}_{0.8} \mathrm{Sm}_{0.2} \mathrm{O}_{1.90}$ was nearly two times that of $\mathrm{Ce}_{0.85} \mathrm{Sm}_{0.15} \mathrm{O}_{2-\delta}$ (MS-SDC), $\mathrm{Ce}_{0.85} \mathrm{La}_{0.15} \mathrm{O}_{2-\delta}$ (MS-LDC), and $\mathrm{Ce}_{0.80} \mathrm{Gd}_{0.20} \mathrm{O}_{1.90}$.

The slope of the conductivity curve in Fig. 5 also shows that a bending occurs at $500-550{ }^{\circ} \mathrm{C}$ for almost all samples, which is interpreted as a transition from associated to disassociated behavior in defect clusters, and consequently as a decrease in the activation energy [10]. Moreover, this situation implies that the conduction mechanism changes at a transition temperature. Thus, there are two different conduction mechanisms at different operating temperature regimes. According to the Arrhenius 
plots (in Fig. 5), there are two parts named as low temperature (LT) and high temperature (HT) regimes in which the linearity of the Arrhenius plots change. The activation energy for conduction becomes the sum of activation energy for migration $E_{m}$ and association $E_{a}$ $\left(E=E_{m}+E_{a}\right)$. It can be said that at high temperature regimes, the dopant-oxygen vacancy complex dissociates completely to set free the dopant cations and oxygen vacancy. The oxygen vacancy concentration is known to not depend on temperature and is equivalent to the total concentration of dopant cations. Therefore, the migration enthalpy can be calculated from the slope of Arrhenius plots in the higher temperature regime. A similar behaviour was also observed in earlier studies [21, 23].

\section{Conclusion}

Rare earth doped $\mathrm{Ce}_{0.8} \mathrm{M}_{0.2} \mathrm{O}_{1.90}(\mathrm{M}=\mathrm{Gd}, \mathrm{Nd}, \mathrm{Sm})$ solid solutions with the fluorite structure were prepared by the citrate-complexation method. The rare earth $(\mathrm{M}=\mathrm{Gd}, \mathrm{Nd}, \mathrm{Sm})$ doped ceria particles reveal the cubic fluorite structure of pristine $\mathrm{CeO}_{2}$ with small lattice strains. Dense solid oxide electrolytes were obtained by sintering the pellets at $1400^{\circ} \mathrm{C}$ for $6 \mathrm{~h}$. The relative densities were over $90 \%$ of the theoretical density and these results are consistent with the SEM studies. In accordance with the results of ionic conductivity the highest ionic conductivity value was calculated as $2.77 \times 10^{-2} \mathrm{~S} / \mathrm{cm}$ at $650{ }^{\circ} \mathrm{C}$ for $\mathrm{SDC}$. This value is $31.9 \%$ higher than NDC $\left(2.1 \times 10^{-2} \mathrm{~S} / \mathrm{cm}\right)$ and $10.8 \%$ higher than GDC $\left(2.5 \times 10^{-2} \mathrm{~S} / \mathrm{cm}\right)$ at intermediate temperature of $650^{\circ} \mathrm{C}$. It can be concluded that the current conductivity values make $\mathrm{Ce}_{0.8} \mathrm{Sm}_{0.2} \mathrm{O}_{1.90}$ a potential candidate material to be used as a solid electrolyte in IT-SOFCs.

\section{Acknowledgments}

The author thanks to Dr. Azade YELTEN for technical discussions. This work was financially supported by Scientific Research Project Coordination Unit of Istanbul University (grant number: 32898).

\section{References}

[1] B.C.H. Steele, Solid State Ionics 129, 95 (2000).

[2] S.P.S. Badwal, K. Foger, Ceram. Int. 22, 257 (1996).

[3] A. Arabac1, Emerg. Mater. Res. 9, 1 (2020).

[4] B. Madhavan, A.K. Kunhiraman, V. Ragavi, Emerg. Mater. Res. 9, 1 (2020).

[5] M. Cengiz Toklu, H. Taşkın, IJCESEN 4, 6 (2018).

[6] H. Inaba, H. Tagawa, Solid State Ionics 83, 1 (1996).

[7] G.B. Jung, T.J. Huang, M.H. Huang, C.L. Chang, J. Mater. Sci. 36, 5839 (2001).

[8] T. Mori, J. Drennan, J.H. Lee, J.G. Li, T. Ikegami, Solid State Ionics 154, 461 (2002).

[9] H. Yahiro, Y. Eguchi, K. Eguchi, H. Arai, J. Appl. Electro-Chem. 185, 909 (1988).

[10] D.R. Ou, T. Mori, F. Ye, J. Zou, J. Drennan, Renew. Energy 33, 197 (2008).

[11] M. Guo, J. Lu, Y. Wu, Y. Wang, M. Luo, Langmuir. 27(7), 3872-7 (2011).

[12] S. Zha, C. Xiang. G. Meng, J. Power Sources 115 44 (2003).

[13] R.D. Purohit, B.P. Sharma, K.T. Pillai, A.K. Tyagi, Mater. Res. Bull. 36, 2711 (2001).

[14] T. Mahata, G. Das, R.K. Mishra, B.P. Sharma, J. Alloys Compd. 391, 129 (2005).

[15] H. Xu, H.Yan, Z.Chen, J. Power Sources 163, 409 (2006).

[16] A. Arabacı, Solid State Ionics 326, 69 (2018).

[17] S. Shrestha, C.M.Y. Yeung, C. Nunnerley, S.C. Tsang, Sens. Actuators A A136, 191 (2007).

[18] J. Tartaj, V. Gil, A. Moure, J. Power Sources 195, 2800 (2010).

[19] N. Shehata, K. Meehan, M. Hudit, N. Jain, J. Nanopart. Res. 14, 1173 (2012).

[20] T. Badapanda, V. Senthil, S.K. Raut, S. Panigrahi, T.P. Sinha, Mat. Chem. Phys. 133, 863 (2012).

[21] M. Gupta, S. Shirbhate, P. Ojha, S. Acharya, Solid State Ionics 320, 199 (2018).

[22] Y.P. Fu, S.H. Chen, J.J. Huang, Int. J. Hydrog. Energy 35, 745 (2010).

[23] J.S. Kilner, C.D. Waters, Solid State Ionics 6, 253 (1982). 